\title{
Assessment and evaluation of symptomatic steroid-naive asthmatics without sputum eosinophilia and their response to inhaled corticosteroids
}

\author{
P. Godon*, L-P. Boulet*, J-L. Malo*, A. Cartier*, C. Lemière*
}

\begin{abstract}
Assessment and evaluation of symptomatic steroid-naive asthmatics without sputum eosinophilia and their response to inhaled corticosteroids. P. Godon, L-P. Boulet, J-L. Malo, A. Cartier, C. Lemière. (C) ERS Journals Ltd 2002.

ABSTRACT: Eosinophilic airway inflammation is one of the hallmarks of asthma. Sputum eosinophilia has been suggested as a predictor of the response to inhaled corticosteroids in asthma. This study sought to investigate the proportion of steroidnaive uncontrolled asthmatics without significant sputum eosinophilia $(\leqslant 1 \%)$ and to examine whether sputum eosinophilia could predict the response to inhaled corticosteroids.

A total of 51 mild uncontrolled steroid-naive asthmatics who had not been treated with oral or inhaled corticosteroids for at least 3 months were investigated. The evaluation included a spirometry, methacholine inhalation challenge and sputum induction on two occasions, one at baseline and the other after 1 month of treatment with $250 \mu \mathrm{g}$ twice-daily fluticasone propionate.

Of the 51 subjects, 15 had an eosinophil count $\leqslant 1 \%$, and 46 completed the two visits. Patients with baseline sputum eosinophils $\leqslant 1 \%(n=14)$ were compared with those with sputum eosinophils $>1 \%(n=32)$. The baseline characteristics of these two groups were similar. After 1 month of treatment, respiratory symptoms, quality of life, forced expiratory volume in one second (FEV1) and provocative concentration causing a $20 \%$ fall in FEV1 improved in both groups.

The absence of sputum eosinophilia does not seem to be an indicator of poor response to inhaled corticosteroid treatment in steroid-naive asthmatics. However, this finding needs to be investigated further in a double-blind, placebo-controlled study, entirely designed to answer this question.
\end{abstract}

Eur Respir J 2002; 20: 1364-1369.

*Dept of Chest Medicine, Hôpital du Sacré-Coeur, Montreal and ${ }^{\#}$ Heart and Chest Institute, Hôpital Laval, Sainte Foy, Quebec, Canada.

Correspondence: C. Lemière, Dept of Chest Medicine, Sacré-Coeur Hospital, 5400 West Gouin, Montreal, Quebec, Canada, H4J 1C5.

Fax: 15143383123

E-mail: lemierec@crhsc.umontreal.ca

Keywords: Asthma

eosinophils

induced sputum

inhaled corticosteroids

Received: March 12002

Accepted after revision: June 202002

This study was funded by Réseau en santé respiratoire du FRSQ and GlaxoSmithKline Canada. C. Lemière and J-L. Malo are scholars of the Fonds de la recherche en santé du Québec.

Current asthma definition and guidelines emphasise the importance of airway inflammation in asthma. The eosinophil has been seen as a key cell in the pathophysiology of asthma [1, 2]. The number of eosinophils correlates with the level of airflow obstruction [3]. A correlation between airway hyperresponsiveness and blood [4] or airway [5] eosinophilia has been reported. However, the relationship between eosinophilic inflammation and asthma severity is controversial. Indeed, some studies showed a correlation between sputum eosinophilia and asthma severity [6] whereas others did not [7].

Corticosteroids play a pivotal role in the treatment of the asthma [8-10]. They rapidly reduce the number of eosinophils in the blood and tissues and inhibit their degranulation, suggesting that sputum eosinophilia could be a good predictor of response to inhaled corticosteroids [11]. Moreover, asthmatic patients with eosinophilic inflammation seem to have a better response to inhaled corticosteroids than asthmatics with $<3 \%$ of sputum eosinophils [12]. Similarly, subjects with chronic obstructive pulmonary disease and a low sputum eosinophil count have a poorer

For editorial comments see page 1359. response in terms of airway function following treatment with oral or inhaled corticosteroids than those with sputum eosinophilia [13]. Since some mildly uncontrolled asthmatic patients show no sputum eosinophilic inflammation [14] this study questioned whether or not these subjects could benefit from corticosteroid treatment. Sputum examination provides a unique opportunity to follow eosinophil counts in asthmatic patients closely and reliably, and it can be repeated on several occasions to monitor the therapeutic effects of such medications as inhaled or oral corticosteroids $[15,16]$. In the present study, the prevalence of patients without sputum eosinophilia was investigated. The authors also examined whether percentage of sputum eosinophils was a predictor of short-term response to inhaled corticosteroids and they investigated whether neutrophil counts were increased in asthmatics without sputum eosinophilia compared with asthmatics with sputum eosinophilia.

\section{Methods}

\section{Study design}

Steroid-naive asthmatics were investigated at SacréCoeur Hospital, (Montreal, Qc, Canada) and Laval 
Hospital, (Sainte-Foy, Qc, Canada) on two occasions. On the first visit, spirometry, methacholine inhalation challenge, sputum induction and skin-prick tests were performed. Treatment with inhaled corticosteroids (250 $\mu \mathrm{g}$ fluticasone twice daily as Flovent Diskusß; GlaxoSmithKline, Mississauga, ON, Canada) was instituted for 1 month. One month later the same investigations were repeated and the compliance with treatment was checked by verifying the Diskus counter.

\section{Subjects}

Asthmatic adults were recruited through newspaper advertisements. They were included consecutively in the study regardless of their sputum eosinophil count. All subjects had suboptimal asthma control and complained of daily asthmatic symptoms, requiring daily rescue by $\beta_{2}$ short-acting agonists and/or nocturnal awakenings. None of the patients had been treated with oral or inhaled corticosteroid for at least 3 months prior to the investigation. Asthma was diagnosed according to the current Guidelines for the Diagnosis and Management of Asthma [9]. All subjects who had suffered an upper or lower respiratory infection within the 4 weeks prior to the first visit, and exsmokers or current smokers of $>10$ pack-yrs were excluded.

The study was approved by the participating hospitals' research ethics committees and all subjects provided informed written consent.

\section{Procedures}

Questionnaires were used to document subject characteristics and symptom severity graded on a validated 10-point Borg scale [17] and quality of life questionnaire [18]. Spirometry was performed according to the American Thoracic Society standards [19]. Methacholine challenge tests were performed as previously described [20]. Sputum was induced using inhalations of increasing concentrations $(3,4$ and $5 \%)$ of hypertonic saline [21] and processed as previously described [22]. Allergy skin-prick tests with commercial extracts from common allergens were performed using the modified prick method; results were regarded as positive if the weal was $\geqslant 3 \mathrm{~mm}$. Compliance with medication was checked by verifying the counters on the Flovent Diskus $\mathbb{R}$ inhalers used by the subjects during the study.

\section{Analysis}

Results were expressed as mean $\pm \mathrm{SD}$, except for data with nonnormal distribution, which were expressed as median and interquartile range. Unpaired t-test and the Wilcoxon signed-rank test were used to compare provocative concentration causing a $20 \%$ fall in forced expiratory volume in one second (FEV1), (PC20) and cell counts, respectively, before and after treatment. The unpaired t-test was used to compare the normally distributed data between asthmatics with and without sputum eosinophilia, and the Mann-Whitney test was used to compare cell counts between these same groups. Correlations between sputum eosinophils, $\mathrm{PC}_{20}$ and FEV1 before and after treatment, as well as their difference between baseline and after treatment, were examined using Spearman's rank-order test. Subjects without sputum eosinophilia were defined a priori as subjects with sputum eosinophils $\leqslant 1 \%$, which corresponds to the values of healthy subjects [23]. However, the same calculations were also performed with an upper cut-off limit of 3\% for sputum eosinophilia. Significance was accepted at the level of $95 \%$.

\section{Results}

A total of 51 subjects met the inclusion criteria and were enrolled. Among them, 46 subjects completed the study. Five subjects were excluded; three because of the occurrence of a respiratory infection between the two visits and two because of noncompliance. Fourteen exsmokers and five current smokers were enrolled; they smoked $5.1 \pm 3$ pack-yrs.

Of the 51 mildly uncontrolled asthmatic subjects who attended the first visit, $15(29.4 \%)$ had a sputum eosinophil count $\leqslant 1 \%$, and $23(45.1 \%)$ had an eosinophil count $\leqslant 3 \%$. Of the 46 subjects who completed the two visits, $12(26 \%)$ had a sputum eosinophil count $\leqslant 1 \%$ at baseline and $21(45.6 \%)$ had a sputum eosinophil count $\leqslant 3 \%$.

Comparison between asthmatics with and without sputum eosinophilia

Baseline demographic, clinical and functional characteristics of the two groups (with and without sputum eosinophilia) were similar (tables 1 and 2) except for sputum eosinophil counts. After 1 month of treatment with inhaled corticosteroids, both groups had significant improvements in clinical (symptom score, quality of life) and functional (FEV1, PC20) parameters (table 2). Similar results were obtained with a cut-off of $3 \%$ for sputum eosinophilia (table 3 ). Subjects with sputum eosinophilia at baseline decreased their eosinophil count significantly after treatment.

Table 1.-Characteristics of the subjects at baseline

Eosinophils $<1 \%$ Eosinophils $>1 \%$

\begin{tabular}{lcc}
\hline Subjects n & 14 & 32 \\
Sex F & 7 & 13 \\
Age yrs & $34.3 \pm 11.6$ & $30.7 \pm 11.0$ \\
Atopy n & 11 & 32 \\
Smoking habits n & 6 & 21 \\
$\quad$ NS & 6 & 8 \\
ES & 2 & 3 \\
CS & $5.0 \pm 4.3$ & $5.1 \pm 4.4$ \\
\hline
\end{tabular}

Data are presented as mean \pm SD unless otherwise stated. F: female; NS: nonsmoker; ES: exsmoker; CS: current smoker. Atopy was defined by the presence of at least one positive skin-prick test. 
Table 2. - Clinical, functional and biological characteristics of subjects with and without sputum eosinophilia before and after treatment with inhaled corticosteroids

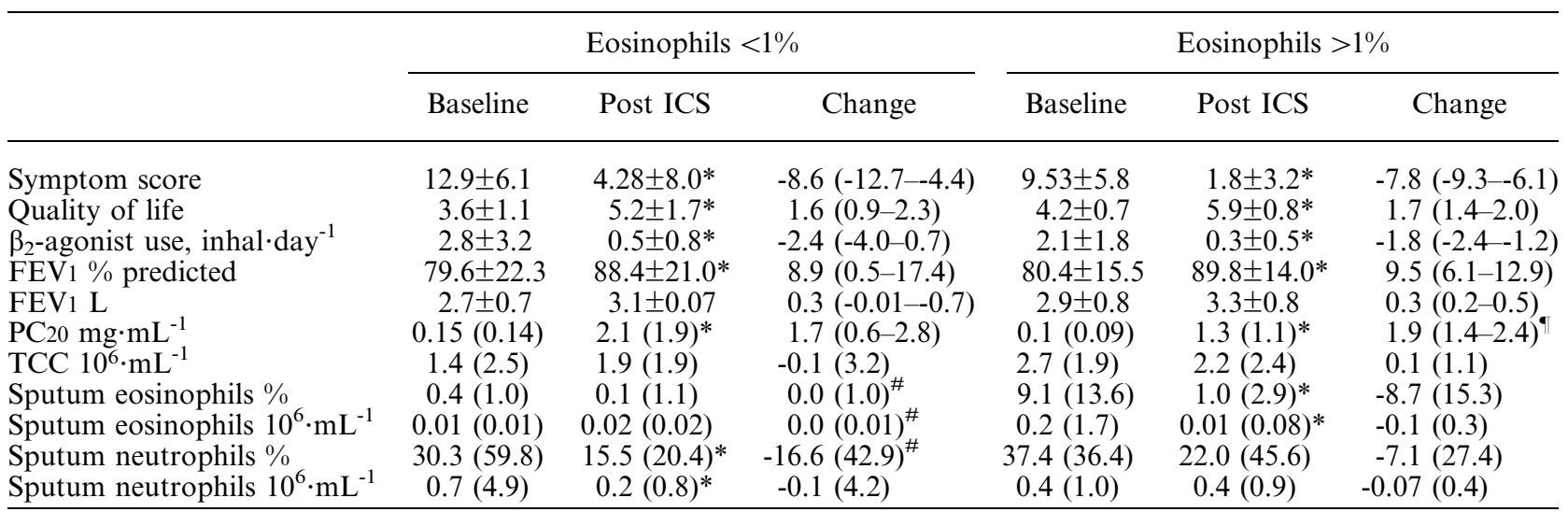

Data are presented as mean $\pm \mathrm{SD}$, median (interquartile range), or mean $(95 \%$ confidence interval). ICS: inhaled corticosteroids; FEV1: forced expiratory volume in one second; PC20: provocative dose causing a 20\% fall in FEV1; TCC: total cell count. *: $\mathrm{p}<0.05$ for comparison between baseline and post-treatment with ICS within groups with and without sputum eosinophilia; ${ }^{\#}$ : $\mathrm{p}<0.05$ for comparison between groups with and without sputum eosinophilia; ": difference in PC20 expressed by difference in doubling dose of methacholine.

Table 3. - Clinical, functional and biological characteristics of subjects with sputum eosinophil count lower and greater or equal to $3 \%$ before and after treatment with inhaled corticosteroids

\begin{tabular}{|c|c|c|c|c|c|c|}
\hline & \multicolumn{3}{|c|}{ Eosinophils $<3 \%$} & \multicolumn{3}{|c|}{ Eosinophils $\geqslant 3 \%$} \\
\hline & Baseline & Post ICS & Change & Baseline & Post ICS & Change \\
\hline Symptom score & $12.0 \pm 5.7$ & $3.4 \pm 6.7 *$ & $-8.6(-11.3-5)-5$ & $9.4 \pm 6.2$ & $1.8 \pm 3.4 *$ & $-7.5(-9.5--5.5)$ \\
\hline Quality of life & $3.8 \pm 1.0$ & $5.4 \pm 1.1 *$ & $1.6(1.2-2.1)$ & $4.2 \pm 0.7$ & $5.9 \pm 0.8^{*}$ & $1.7(1.4-2.0)$ \\
\hline$\beta_{2}$-agonist use inhal $\cdot$ day $^{-1}$ & $2.4 \pm 2.7$ & $0.4 \pm 0.7 *$ & $-2(-3.1-0.9)$ & $2.3 \pm 1.9$ & $0.4 \pm 0.5^{*}$ & $-1.9(-2.6-1.2)$ \\
\hline FEV $1 \%$ pred & $83.5 \pm 21.1$ & $90.4 \pm 19.5$ & $6.9(1.2-12.5)$ & $77.3 \pm 14.8$ & $88.6 \pm 13.2$ & $11.3(7.4-15.3)$ \\
\hline FEV1 L & $3.0 \pm 0.08$ & $3.2 \pm 0.8^{*}$ & $0.3(0.03-0.5)$ & $2.8 \pm 0.7$ & $3.2 \pm 0.8^{*}$ & $0.4(0.2-0.6)$ \\
\hline $\mathrm{PC} 20 \mathrm{mg} \cdot \mathrm{mL}^{-1}$ & $0.3(0.33)$ & $2.9(2.5)^{*}$ & $1.7(0.9-2.4)^{\top}$ & $0.05(0.05)$ & $1.1(0.9)^{*}$ & $2.0(1.5-2.6)$ \\
\hline TCC $10^{6} \cdot \mathrm{mL}^{-1}$ & $1.7(2.6)$ & $2.1(2.7)$ & $0.08(2.6)$ & $2.0(1.9)$ & $2.0(2.4)$ & $0.08(3.3)$ \\
\hline Sputum eosinophils $\%$ & $1.0(1.6)$ & $0.3(1.3)$ & $-0.4(1.2)^{\#}$ & $12.1(14.2)$ & $1.0(3.6)^{*}$ & $-10.4(14.3)$ \\
\hline Sputum eospinophils $10^{6} \cdot \mathrm{mL}^{-1}$ & $0.03(0.04)$ & $0.02(0.03)$ & $-0.004(0.02)$ & $0.4(0.4)$ & $0.07(0.1)^{*}$ & $-0.3(0.4)$ \\
\hline Sputum neutrophils \% & $42.9(59.6)$ & $20.4(24.9)^{*}$ & $-9.9(40.4)$ & $37.4(26.5)$ & $18.2(41.7)$ & $-10.5(30.7)$ \\
\hline Sputum neutrophils $10^{6} \cdot \mathrm{mL}^{-1}$ & $0.5(2.9)$ & $0.3(0.9)^{*}$ & $-0.1(2.4)$ & $0.4(0.9)$ & $0.4(0.8)$ & $-0.07(0.5)$ \\
\hline
\end{tabular}

Data are presented as mean $\pm \mathrm{SD}$, median (interquartile range), or mean $(95 \%$ confidence interval). ICS: inhaled corticosteroids; FEV1: forced expiratory volume in one second; PD20: provocative dose causing a 20\% fall in FEV1; TCC: total cell count. $*$ p $<0.05$ for comparison between baseline and post-treatment with ICS within groups with and without sputum eosinophilia; ${ }^{\#}: p \leqslant 0.05$ for comparison between groups with and without sputum eosinophilia; ${ }^{*}$ : difference in PC20 is expressed by difference in doubling dose of methacholine.

This study was adequately powered (power $=90 \%$ ) to detect a minimum difference of 0.5 in $\log \mathrm{PC} 20$ between both groups, which represents a 3.2-fold difference in PC20 with an $\alpha$ of 0.05 . This difference represents the limit of reproducibility in the authors' centre and is considered to be clinically significant [24]. However, this study was underpowered to show significant differences in FEV1 since it showed a power of $71 \%$ to detect a difference of $20 \%$ in FEV1 between both groups.

For the group of subjects with baseline sputum eosinophilia, a significant correlation was found between the percentage of sputum eosinophils at baseline and the improvement of FEV1 (correlation coefficient (rho) $=0.52, \mathrm{p}=0.002$ ). A negative correlation between the changes in sputum eosinophils and FEV1 after treatment was also found (rho=-0.6, $\mathrm{p}<0.001$; fig. 1). There was no significant correlation between the change in $\mathrm{PC}_{20}$ after treatment and the percentage of eosinophils at baseline (rho $=0.16$, $p=0.37$ ), or the decrease in sputum eosinophils after treatment with inhaled corticosteroids (rho $=-0.15$, $\mathrm{p}=0.4$; fig. 1). There was no correlation between the changes in sputum eosinophils and the improvement of symptoms or quality of life.

Sputum neutrophils in asthmatics with and without sputum eosinophilia

Although the median sputum neutrophil counts were similar at baseline in the groups with and without sputum eosinophilia, there was a more marked reduction in median sputum neutrophils 

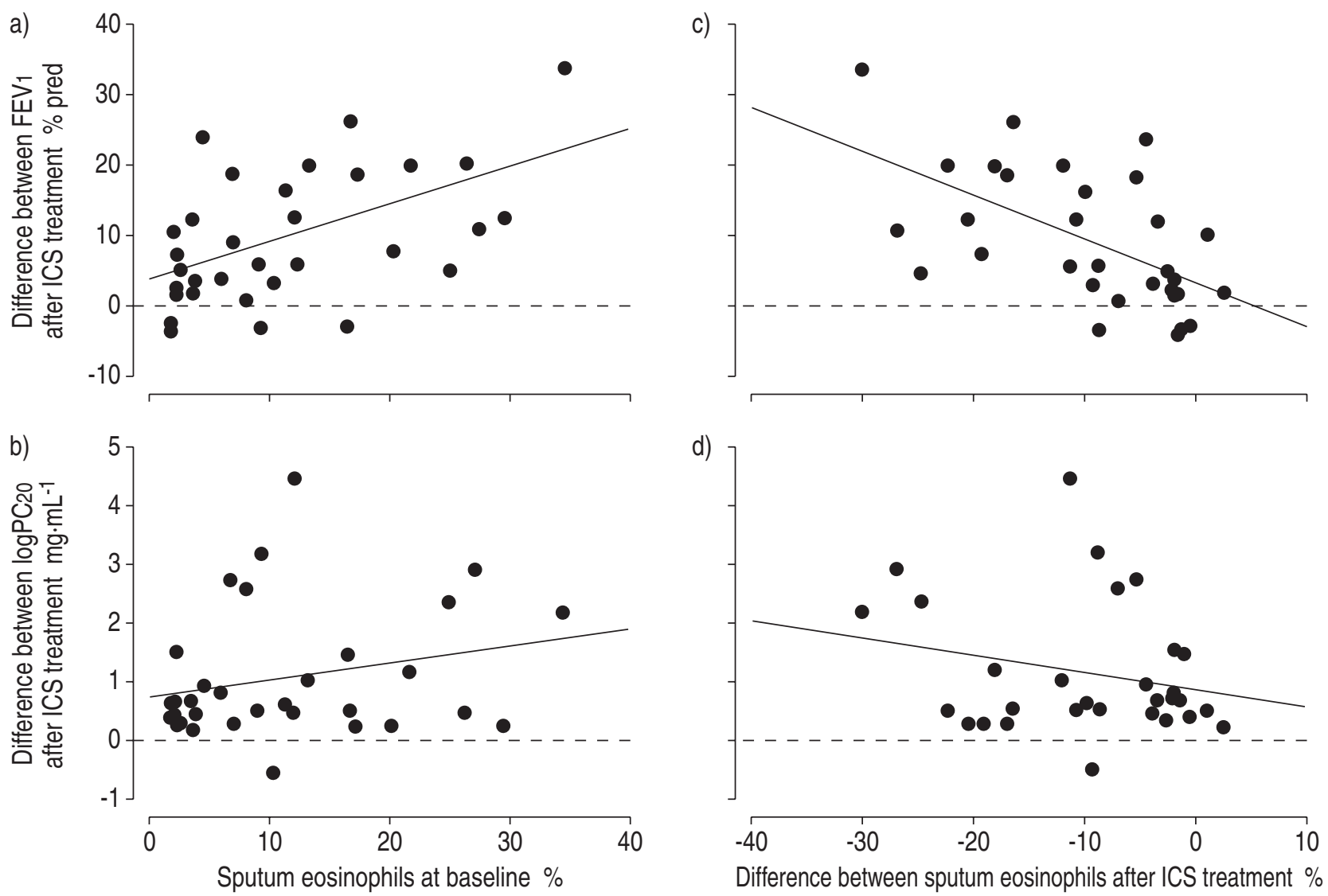

Fig. 1.-Correlation between sputum eosinophil count at baseline and change in sputum eosinophils after treatment with inhaled corticosteroids (ICS) and change in forced expiratory volume in one second (FEV1) and provocative dose causing a $20 \%$ fall in FEV1. a) $\mathrm{rho}=0.52$, $=0.002$; b) rho $=0.16, \mathrm{p}=0.37$; c) $\mathrm{rho}=-0.6, \mathrm{p}<0.001$; $) \mathrm{rho}=-0.15, \mathrm{p}=0.4$.

among the subjects without eosinophilia (-16.6 $(42.9) \%$ ) than among subjects with sputum eosinophilia $(-7.1(27.4) \% ; \mathrm{p}=0.05)$ after treatment. However, the reduction in absolute neutrophil count after inhaled corticosteroid treatment was not significantly different between the two groups. Four subjects without baseline sputum eosinophilia had a high sputum neutrophil count $(>65 \%)$; two of these also had a high total cell count greater than $10 \times 10^{6}$ cells. However, they had no clinical evidence of respiratory infection. One of these subjects increased his eosinophil count from 0.3 to $5.5 \%$ after treatment with inhaled corticosteroids. There was no correlation found between sputum neutrophil count and clinical (symptom and quality of life score) or functional (FEV1 and PC20) parameters.

\section{Discussion}

In this study, it was found that $29 \%$ of 51 mildly uncontrolled steroid-naive asthmatics had a sputum eosinophil count $<1 \%$. After 1 month of treatment with inhaled corticosteroids, the respiratory symptoms and functional parameters of subjects without baseline sputum eosinophilia improved significantly.

Recently, GiBson et al. [25] found that among 56 asthmatics receiving high doses of inhaled corticosteroids,
$59 \%$ had a sputum eosinophil count $<2.5 \%$. In this study, approximately the same proportion $(45 \%)$ of steroid-naive subjects with a sputum eosinophil count of $<3 \%$ were found.

The findings of this study differ from previous studies, which showed subjects without sputum eosinophilia did not improve as much as those with sputum eosinophilia after treatment with inhaled corticosteroids [12]. The present study had a more stringent cut-off for sputum eosinophilia $(1 \%)$ than previous studies (3\%) [2]. However, it is unlikely that the choice of cut-off explains the discrepancy as similar results have been obtained when the cut-off for sputum eosinophilia was set at 3\%. The present study may have lacked power to identify differences in some indices such as FEV1 between the groups with and without sputum eosinophilia. Indeed, the primary outcome of this study was to evaluate the proportion of mildly uncontrolled steroid-naive asthmatic subjects who did not show sputum eosinophilia. The sample size was not calculated for demonstrating a significant difference in functional parameters such as FEV1 or $\mathrm{PC}_{20}$ between subjects with and without sputum eosinophilia as the number of subjects in each group could not be predicted. Nevertheless, the study was adequately powered $(90 \%)$ to detect a clinically significant difference in airway responsiveness between the two groups and therefore it can be stated that the 
improvement of PC20 was similar in both groups. In subjects with baseline sputum eosinophils $>1 \%$, a positive correlation was shown between the baseline sputum eosinophil count and improvement in FEV1 after treatment with inhaled corticosteroids. This was found to be consistent with previous findings [12]. However, there was no correlation between baseline sputum eosinophils and improvement of airway hyperresponsiveness. This observation suggests that eosinophilic airway inflammation may be responsible for or associated with a process leading to airflow limitation, but that it is not closely linked with airway responsiveness, which is consistent with previous findings [26]. A greater improvement of FEV1 may have been detected in the group with sputum eosinophilia compared with the group without sputum eosinophilia in this study, if it had been powered to detect significant differences in FEV1 between the two groups.

It is possible that the subjects in this study without sputum eosinophil had higher eosinophil counts in their bronchial mucosa than in their bronchial lumen, as the correlation between sputum eosinophils and eosinophils in the bronchial mucosa has been found to be weak or absent $[27,28]$. It is also possible that some fluctuations in baseline sputum eosinophil counts occurred. However, it was shown previously that the reproducibility of the eosinophil count performed on two separate occasions within a 6-day period is good [22]. It is therefore unlikely that the group without sputum eosinophilia had a high eosinophil count within the week of the first measurement.

It can be argued that this study did not include a placebo group and that the group of subjects without sputum eosinophilia would have improved even on placebo. Although this concern cannot be answered, it is unlikely that such a consistent and marked improvement in all clinical and functional parameters would have occurred in asthmatics treated with placebo. Moreover, although the placebo effect may have affected the pre- and post-treatment comparison, the effect is supposed to be similar in both groups and should not have interfered with the comparison between the two groups.

GiBson et al. [25] found that subjects with eosinophils $<2.5 \%$ also had higher neutrophil counts. The subjects in this study, without sputum eosinophilia did not show higher neutrophil counts than subjects with sputum eosinophilia. This discrepancy may be explained by the absence of treatment with inhaled corticosteroids at baseline in the subjects in this study. Indeed, corticosteroids might induce neutrophilic inflammation by mechanisms such as the reduction of neutrophil apoptosis [29]. It is possible, although not clinically evident, that some subjects with both a high neutrophil count and a high total cell count had a poor control of their asthma because of a respiratory infection. In these subjects, sputum eosinophilia may have been masked by the massive increase in neutrophils. Consistent with this hypothesis, two subjects increased their eosinophil count after inhaled corticosteroids. In these subjects, the decrease in neutrophil counts may have been due to the resolution of the infection.
Glucocorticoids inhibit eosinophil migration and degranulation but also suppress multiple components of allergic airway inflammation such as cell recruitment, vascular leakage and production of various cytokines (interleukin-2, 4, 5 and T-cell growth factor) [30]. Therefore, it is not surprising that the absence of sputum eosinophilia itself fails to predict the effect of the treatment with inhaled corticosteroids in the subgroup without sputum eosinophilia.

In conclusion, it was found that a fair proportion $(29 \%)$ of mildly uncontrolled steroid-naive asthmatics do not show sputum eosinophilia. Although asthmatic subjects with high eosinophil counts seem to have a larger improvement of their forced expiratory volume in one second after inhaled steroid treatment than subjects with low eosinophil counts, the absence of sputum eosinophils does not seem to be an indicator of a poor overall response to inhaled steroid treatment in these subjects. However, this question will only be fully answered by a double-blind, placebo-controlled trial comparing the response of symptomatic asthmatics without sputum eosinophilia after treatment with inhaled steroid, to their response after treatment with placebo.

\footnotetext{
Acknowledgements. The authors would like to thank S. Chaboillez, and J. Milot for their active participation in the study and L. Schubert for reviewing the manuscript.
}

\section{References}

1. Gleich G. The eosinophil and bronchial asthma: Current understanding. J Allergy Clin Immunol 1990; 85: 422-436.

2. Frigas E, Gleich G. The eosinophil and the pathophysiology of asthma. J Allergy Clin Immunol 1986; 77: 527-537.

3. Virchow JC Jr, Holscher U, Virchow C Sr. Sputum ECP levels correlate with parameters of airflow obstruction. Am Rev Respir Dis 1992; 146: 604-606.

4. Taylor K, Luksza A. Peripheral blood eosinophil counts and bronchial responsiveness. Thorax 1987; 42: $452-456$.

5. Woodruff PG, Khashayar R, Lazarus SC, et al. Relationship between airway inflammation, hyperresponsiveness, and obstruction in asthma. J Allergy Clin Immunol 2001; 108: 753-758.

6. Louis R, Lau LC, Bron AO, Roldaan AC, Radermecker M, Djukanovic R. The relationship between airways inflammation and asthma severity. Am J Respir Crit Care Med 2000; 161: 9-16.

7. Ronchi MC, Piragino C, Rosi E, et al. Do sputum eosinophils and ECP relate to the severity of asthma? Eur Respir J 1997; 10: 1809-1813.

8. National Heart, Lung and Blood Institute. Guidelines for the diagnosis and management of asthma. $J$ Allergy Clin Immunol 1991; 88: 425-534.

9. Boulet LP, Becker A, Berube D, Beveridge R, Ernst P. Canadian Asthma Consensus Report, 1999. Canadian Asthma Consensus Group. CMAJ 1999; 161: S1-S61.

10. Boulet LP, Becker A, Berube D, Ernst P, Beveridge R. 
1998 revision of the Canadian Asthma Consensus Guidelines. Asthma Consensus Conference Editorial Committee. Can Respir J 1999; 6: 231-232.

11. Hargreave FE. Induced sputum and response to glucocorticoids. J Allergy Clin Immunol 1998; 102: S102-S105.

12. Pavord ID, Brightling CE, Woltmann G, Wardlaw AJ. Non-eosinophilic corticosteroid unresponsive asthma. Lancet 1999; 353: 2213-2214.

13. Pizzichini E, Pizzichini MM, Gibson P, et al. Sputum eosinophilia predicts benefit from prednisone in smokers with chronic obstructive bronchitis. Am J Respir Crit Care Med 1998; 158: 1511-1517.

14. Turner M, Hussack P, Sears M, Dolovich J, Hargreave F. Exacerbations of asthma without sputum eosinophilia. Thorax 1995; 50: 1057-1061.

15. Pizzichini MM, Pizzichini E, Clelland L, et al. Sputum in severe exacerbations of asthma: kinetics of inflammatory indices after prednisone treatment. Am J Respir Crit Care Med 1997; 155: 1501-1508.

16. Kips JC, Fahy JV, Hargreave FE, Ind PW, In't VJ. Methods for sputum induction and analysis of induced sputum: a method for assessing airway inflammation in asthma. Eur Respir J 1998; 26: 9S$12 \mathrm{~S}$.

17. Borg GA. Psychophysical bases of perceived exertion. Med Sci Sports Exerc 1982; 14: 377-381.

18. Juniper E, Guyatt G, Ferrie P, Griffith L. Measuring quality of life in asthma. Am Rev Respir Dis 1993; 147: 832-838.

19. American Thoracic Society. Standardization of spirometry. 1994 update. Am J Respir Crit Care Med 1995; 152: 1107-1136.

20. Juniper EF, Cockcroft DW, Hargreave FE. Histamine and methacholine inhalation test: a laboratory tidal breathing protocol. Lund, Sweden, Astra Draco AB, 1994.

21. Pin I, Gibson P, Kolendowicz F, et al. Use of induced sputum cell counts to investigate airway inflammation in asthma. Thorax 1992; 47: 25-29.

22. Pizzichini E, Pizzichini M, Efthimiadis A, et al. Indices of airway inflammation in induced sputum: reproducibility and validity of cell and fluid-phase measurements. Am J Respir Crit Care Med 1996; 154 : 308-317.

23. Belda J, Leigh R, Parameswaran K, O'Byrne PM, Sears MR, Hargreave FE. Induced sputum cell counts in healthy adults. Am J Respir Crit Care Med 2000; 161: 475-478

24. Dehaut P, Rachiele A, Martin R, Malo J. Histamine dose-response curves in asthma: reproducibility and sensitivity of different indices to assess response. Thorax 1983; 38: 516-522.

25. Gibson PG, Simpson JL, Saltos N. Heterogeneity of airway inflammation in persistent asthma: evidence of neutrophilic inflammation and increased sputum interleukin-8. Chest 2001; 119: 1329-1336.

26. Crimi E, Spanevello A, Neri M, Ind P, Rossi G, Brusaco V. Dissociation between airway inflammation and airway hyperresponsiveness in allergic asthma. Am J Respir Crit Care Med 1998; 157: 4-9.

27. Maestrelli P, Saetta M, Stefano AD, et al. Comparison of leukocyte counts in sputum, bronchial biopsies, and bronchoalveolar lavage. Am J Respir Crit Care Med 1995; 152: 1926-1931.

28. Grootendorst DC, Sont JK, Willems LN, et al. Comparison of inflammatory cell counts in asthma: induced sputum vs bronchoalveolar lavage and bronchial biopsies. Clin Exp Allergy 1997; 27: 769-779.

29. Cox G. Glucocorticoid treatment inhibits apoptosis in human neutrophils. Separation of survival and activation outcomes. J Immunol 1995; 154: 4719-4725.

30. Liu MC, Proud D, Lichtenstein LM, et al. Effects of prednisone on the cellular responses and release of cytokines and mediators after segmental allergen challenge of asthmatic subjects. $J$ Allergy Clin Immunol 2001; 108: 29-38. 